\title{
COVID-19 Tanısı Alan Çocukların İmmüno-Hematolojik Açıdan Değerlendirilmesi
}

\section{Immuno-Hematological Evaluation of Children with COVID-19 Diagnosis}

\author{
Mehmet Fatih Orhan ${ }^{1}$, Öner Özdemir ${ }^{2}$ \\ ${ }^{1}$ Sakarya Üniversitesi Tip Fakültesi, Çocuk Hematolojisi ve Onkolojisi Bilim Dal, Sakarya, Türkiye \\ ${ }^{2}$ Sakarya Üniversitesi Tip Fakültesi, Çocuk İmmünolojisi ve Alerji Hastalıkları Bilim Dalı, Sakarya, Türkiye \\ Yazışa Adresi / Correspondence: \\ Mehmet Fatih Orhan \\ Sağlık Cad. No: 195 Sakarya Üniversitesi Tip Fakültesi Eğitim ve Araștırma Hastanesi, Çocuk Hematolojisi ve Onkolojisi Bilim Dalı, 54100 Adapazarı/Sakarya. \\ T: +905065349907 E-mail: forhan@sakarya.edu.tr
}

Geliş Tarihi / Received : 04.04.2021 Kabul Tarihi / Accepted: 27.07.2021

Orcid :

Mehmet Fatih Orhan https://orcid.org/0000-0001-8081-6760

Öner Özdemir https://orcid.org/0000-0002-5338-9561

( Sakarya Tip Dergisi / Sakarya Med J 2021, 11(4):823-828 ) DOI: 10.31832/smj.908894

\begin{abstract}
Öz
Amaç COVID-19, çocuklarda yetişkinlerle karşılaştırıldığında nispeten daha hafif klinik semptomlarla seyretmektedir. Bu çalıșmada, tanı sırasında gözlenen hematolojik ve immünolojik değişiklikleri irdelemeyi amaçladık.

Yöntem ve Çalışmaya 22 (6 kız, 16 erkek) COVID-19 hastası alındı. Etik kuruldan onay alındı. COVID-19 hastalarında hematolojik parametreler olarak hemogram, protrombin Gereçler zamanı (PT), aktive parsiyel tromboplastin zamanı (aPTT), fibrinojen, D-Dimer ve immünolojik parametre olarak flow sitometri ile lenfosit alt grupları çalışıldı.

Bulgular Hastaların medyan yaşı 8,1 (2,3-17,5) yıl idi. Elde edilen değerlerin, literatürdeki normal değerlerle kıyaslanabilmesi için hastalar yaş gruplarına ayrıldı. Medyan WBC sayısı 6.145 (3.137-11.000) / $\mu \mathrm{L}$ bulundu. Çocukların yașı büyüdükçe beyaz küre sayısı azalma eğiliminde idi. Monosit sayıları açısından gruplar arası fark saptandı. Eozinofil, platelet/lenfosit oranı (PLR), PT, aPTT, fibrinojen, D-Dimer açısından gruplar arasında fark saptanmadı. Hastalarımızın 2-5 yaș grubunda olanlarda helper T hücreleri azalmış ve sitotoksik T hücreleri artmıştı. Buna bağlı olarak da CD4/CD8 oranı yaşa göre normalden düşüktü. Aynı oran düşüklüğü 16 yaş üzerindeki grupta da görüldü. Erişkin yaş grubuna yakın olan 16 yaş üstü grupta CD8 sayısı normale göre düşük bulundu. B hücre sayısı yaşı en küçük olan grupta azalmıșken, en büyük grupta artmıṣ bulundu. NK hücre sayıları da 16 yaş üstü grupta düşük bulunurken diğer yaş gruplarında normal veya artmıs idi.

Sonuç Hemogram çalıșıldığında basitçe elde edilecek platelet-lenfosit oranı (PLR) sitokin fırtınasının bir göstergesi olarak kullanılabilir ve çocuklarda CD8 așırı ekspresyonı olmaması COVID-19 hastalığını neden erişkinlere oranla daha hafif geçirdiklerinin nedeni olabilir. NK hücrelerinin artıșı da bu hastalıktan koruyucu mekanizmalardan biridir.

Anahtar Çocuk; COVID-19; SARS-CoV-2; Platelet-lenfosit oranı; Akım Sitometri

Abstract

Introduction COVID-19 has relatively mild clinical symptoms in children compared to adults. In this study, we aimed to examine the hematological and immunological changes observed during diagnosis.

Materials Twenty-two (6 girls, 16 boys) COVID-19 patients were included in the study. Approval from ethical committee from Sakarya University was obtained. Hemogram, prothrombin and Methods time (PT), activated partial thromboplastin time (aPTT), fibrinogen, D-Dimer as hematological parameters, and lymphocyte subgroups were studied with flow cytometry as immunological parameters in COVID-19 patients.

Results. The median age of the patients was 8.1 (2.3-17.5) years. The patients were divided into age groups in order to compare the detected values with normal values in the literature. The median WBC count was 6.145 (3.137-11.000) / $\mu$ L. As the age of the children increased, the white blood cell count tended to decrease. There was a difference between the groups in terms of the number of monocytes. There was no difference between the groups in terms of eosinophils, platelet / lymphocyte ratio (PLR), PT, aPTT, fibrinogen, $D$-Dimer. Helper $T$ cells decreased, and cytotoxic T cells increased in patients aged 2-5 years. Accordingly, the CD4 / CD8 ratio was lower than normal for age. The same low rate was seen in the group over 16 years old. The CD8 count was found to be lower than normal in the age group above 16, which is close to the adult age group. While the number of B cells decreased in the youngest group, it was found to be increased in the oldest group. NK cell counts were also found to be low in the group over 16 years old, while it was normal or increased in other age groups.
\end{abstract}

Conclusion Platelet-lymphocyte ratio (PLR), which can be detected simply by studying the hemogram, can be used as an indicator of cytokine storm, and the lack of CD8 overexpression in children may be the reason why they experience COVID-19 disease less severe than adults. Increase of NK cells are one of the protective mechanisms from this disease.

Keywords Child; COVID-19; SARS-CoV-2; Platelet-lymphocyte ratio; Flow Cytometry 


\section{GİRIŞ}

Her yaştan insan SARS-CoV-2 enfeksiyonu olan Korona Virüs Hastalığı 2019 (COVID-19)'a karşı duyarlı olmakla birlikte, hastalık çocuklarda yetişkinlerle karşılaştırıldığında nispeten daha hafif klinik semptomlarla seyretmektedir. ${ }^{1} \mathrm{Bu}$ hastalıkta, çocuklarda çoğu zaman da hemogram normal çıkmaktadır. ${ }^{2}$ Lenfopeni, 2003 yılında SARS - CoV ile ilişkili olan Hong Kong ve Singapur'daki hastaların retrospektif analizinde iyi tanımlanmıştır. COVID-19 hastalığında da şiddetli lenfopeni $(<0,6 \times 109 / \mathrm{L})$ yoğun bakıma erken kabul göstergelerinden biri olarak düşünülebilir. ${ }^{3}$ Olumsuz sonuçlar ve yoğun bakımda kalış ile ilişkilendirilmiştir. ${ }^{4}$ Lenfopeni ile seyrettiği konusunda yayınlar gittikçe artmaktadır. Şiddetli COVID-19’un nispeten yüksek bir mortalite ile seyretmesi endişe vericidir. Hemogramda görülebilecek patolojik bulgulardan birisi de trombositopenidir. ${ }^{5}$ Ciddi COVID-19 pnömoni vakalarında trombosit sayısı yanısıra platelet-lenfosit oranı (PLR) dikkate alınan parametrelerden biri olmuştur. Durumu daha ciddi olan hastalarda hematolojik olarak lenfopeni, PT/aPTT uzunluğu ile D-Dimer yüksekliği saptanmıştır. ${ }^{6}$ Literatürde hangi lenfosit alt gruplarının azaldığına dair çalışılmış çok az sayıda araştırma vardır.?

\section{AMAÇ}

Bu araştırmada, COVID - 19 infeksiyonu tanısı alan çocuk hastalarda tanı sırasında ve tedavi sürecinde gözlenen hematolojik ve immünolojik değişiklikleri irdelemeyi amaçladik.

\section{GEREÇ ve YÖNTEMLER}

Çalışmaya, Sakarya Eğitim ve Araştırma Hastanesi Çocuk Sağlığı ve Hastalıkları kliniği acil ve servislerinde, ayaktan/yatarak başvuran, orofarenks/nazofarenks sürüntü örneğinden SARS-CoV-2 PCR testi yapılarak COVID-19 tanısı alan, 0-18 yaş arası 22 çocuk dahil edilmiştir. Sakarya Üniversitesi Tip Fakültesi Etik Kurul'dan 27.05.2020 tarih ve 16214662/050.01.04/107 sayılı karar ile tanımlayıcı çalışma izni alınmıştır. Bu hastaların Hastane Pandemi Kurulu'nun ve Bakanlığın rehberine göre alınmış tüm kan tetkikleri, görüntüleme hizmetleri, hastane bilgi yönetim sistemine ve dosyasına kaydedilmiş bütün notları geriye dönük olarak incelenmiştir. İlaveten sadece 1 mor kapaklı EDTA tüpüne 1-2 ml kan alınmış ve bu tüpten flow sitometrik olarak lenfosit alt grup paneli çalışılmıştır. Kişisel Verilerin Korunması Kanunu'na aykırı olacak hiçbir bilgi toplanmamıştır. Yaşı 0-18 yıl arası olan ve SARS-CoV-2 PCR testi yapılarak COVID-19 tanısı alanlar çalışmaya dahil edilmiştir. Altta yatan immün yetmezliği tanısı almış çocuklar, sürekli steroid tedavisi alanlar, son 15 gün içinde kemoterapi alanlar ve çocuğuna ait hiçbir verinin kullanılmamasına dair özellikle beyanda bulunmuş ebeveynlerin çocukları çalışmaya dahil edilmemiştir. Elde edilen değerler, sağlıklı Türk çocukları için yayınlanmış normallerle kıyaslanmıştır. $^{8}$

Sayısal değişkenlerin normal dağılıp dağılmadığı Kolmogorov-Smirnov testi ile incelendi. Normal dağılım gösteren sayısal değişkenler ortalama \pm standart sapma, normal dağılım göstermeyen sayısal değişkenler medyan (minimum-maksimum) şeklinde, kategorik değişkenler ise sayı ve yüzde ile ifade edildi. Bağımsız grupların sayısal değişkenleri karşılaştırılırken; normal dağılım gösterenlerde Student $\mathrm{t}$ testi, normal dağılım göstermeyenlerde Mann Whitney U testi kullanıldı. Bağımsız gruplar arası kategorik verilerin karşılaştırılması için Chi-Square testi veya Fischer's Exact testi kullanıldı. Sürekli sayısal değişkenlerin birbirleri arasında anlamlı korelasyon olup olmadığ 1 Pearson ve Spearman'in sıra sayıları korelasyon analizleri ile, lineer ilişkileri ise lineer regresyon analizi kullanılarak yapılmıştır. İstatistiksel analizler IBM SPSS Statistics for Windows, Version 21.0. (IBM Corp. Armonk, NY: USA. Released 2012) paket programı kullanılarak yapılmıştır. Tüm analizlerde $\mathrm{p}<0,05$ anlamlılık düzeyi olarak kabul edilmiştir.

\section{BULGULAR}

Çalışmaya alınan 22 çocuktan (6 kız, 16 erkek) elde edilen değerlerin, literatürdeki normal değerlerle kiyaslanabilmesi için araştırma grubu yaş gruplarına ayrıldı. 2-5 yaş gru- 
buna 8, 5-10 yaş grubuna 5, 10-16 yaş grubuna 7 ve 16 yaş üstü gruba 2 çocuk düşmüştür. Tüm çocukların medyan yaşı 8,1 (2,3-17,5) yıl olarak hesaplandı. Hasta grubumuzu Çocuk kliniği acil ve servislerine, ayaktan/yatarak başvuran vakalar oluşturmakla beraber, hiçbiri yoğun bakım ihtiyacı ve/veya Sağlık Bakanlığg’nın önerdiği rutin tedavi dışında başka bir müdahele gerektirmemiştir.

Medyan WBC sayısı 6.145 (3.137-11.000)/ $\mu$ L sayıldı. Çocuklar büyüdükçe beyaz küre sayısı azalma eğiliminde idi. Monosit ve eozinofil sayıları açısından gruplar arasında bir fark saptanmadi. Gruplar arasında platelet-lenfosit oranında (PLR) bir fark saptanmadı. PT/aPTT, fibrinojen ve D-Dimer değerleri açısından da gruplar arasında istatistiksel olarak anlamlı bir fark yoktu (Tablo 1).

Yaş grupları arttıkça lenfosit yüzdeleri azalma eğiliminde idi (Şekil 1). Fakat bu istatistiksel olarak anlamlı değildi $(p=0,089)$. Yaşa göre normal referans değerler baz alındı- ğında lenfopenisi olan hiçbir hasta yoktu.

CD3+ ve CD4+ T hücre sayısı ortancaları açısından gruplar arasında istatistiki olarak anlamlı bir fark vardı $(\mathrm{p}=0,018$ ve $\mathrm{p}=0,020)$. Lenfositler, yaşa göre normal değerlerle karşılaştırıldığında 2-5 yaş grubunda hem yüzde hem de mutlak sayı olarak artmış bulundu (Tablo 2). Lenfosit alt grupları irdelendiğinde $\mathrm{T}$ hücre sayıları tüm yaş gruplarında normaldi. Sadece 2-5 yaş grubunda helper T hücreleri azalmış ve sitotoksik T hücreleri artmıştı. Buna bağlı olarak da CD4/CD8 oranı yaşa göre normalden düşüktü. Aynı oran düşüklüğü 16 yaş üzerindeki grupta da görüldü. İlave olarak erişkin yaş grubuna yakın olan 16 yaş üstü grupta CD8 sayısı normale göre düşük bulundu.

B hücre sayısı yaşı en küçük olan grupta azalmışken, en büyük grupta artmış bulundu. NK hücre sayıları da 16 yaş üstü ve 5-10 yaş grupta düşük bulunurken diğer yaş (2-5 yaş) gruplarında normal veya artmış idi (Tablo 2).

Tablo 1: COVID -19 tanılı çocuklarda hematolojik ve koagülometrik parametrelerin yaş gruplarına göre medyan değerleri*

\begin{tabular}{|c|c|c|c|c|c|c|}
\hline & $\begin{array}{c}2-5 \text { Yaş } \\
(\mathrm{n}=8)\end{array}$ & $\begin{array}{c}5-10 \text { Yaş } \\
(n=5)\end{array}$ & $\begin{array}{c}10-16 \text { Yaş } \\
(\mathrm{n}=7)\end{array}$ & $\begin{array}{l}16 \text { Yaş üstü } \\
(n=2)\end{array}$ & Tüm çocuklar & $\mathrm{p}$ \\
\hline Yaş & $2,6(2,3-3,6)$ & $6,9(5,2-9,7)$ & $13,5(11,5-15,5)$ & $16,7(15,8-17,5)$ & $8,1(2,3-17,5)$ & \\
\hline $\mathrm{WBC}(/ \mu \mathrm{L})$ & $7315(3137-11000)$ & $7010(5420-9170)$ & $6110(4690-6740)$ & $5180(4190-6170)$ & $6145(3137-11000)$ & 0,089 \\
\hline Monosit (\%) & $9(3-11)$ & $12(9-15)$ & $8(5-12)$ & $11(10-11)$ & $10(3-15)$ & 0,651 \\
\hline Monosit $(/ \mu \mathrm{L})$ & $426(258-1180)$ & $865(488-1070)$ & $520(231-637)$ & $548(457-639)$ & $539(231-1180)$ & 0,475 \\
\hline Eozinofil (\%) & $2(1-5)$ & $3(1-11)$ & $2(0-4)$ & $1(1-2)$ & $2(0-11)$ & 0,522 \\
\hline Eozinofil $(/ \mu \mathrm{L})$ & $196(26-356)$ & $224(39-615)$ & $89(25-247)$ & $70(35-104)$ & $163(25-615)$ & 0,607 \\
\hline Trombosit $(\mathrm{K} / \mu \mathrm{L})$ & $247(162-356)$ & $244(182-305)$ & $196(120-333)$ & $166(158-174)$ & $225(120-356)$ & 0,542 \\
\hline PLR & $74(47-90)$ & $76(55-135)$ & $86(60-170)$ & $69(51-87)$ & $77(47-170)$ & 0,716 \\
\hline PT (sn) & $12.1(11.0-13.6)$ & $11.6(10.4-16.9)$ & $12.4(11.6-14.2)$ & $12.4(12.0-12.7)$ & $12.1(10.4-16.9)$ & 0,523 \\
\hline Fibrinojen $(\mathrm{mg} / \mathrm{dL})$ & $276(199-373)$ & $343(253-409)$ & $253(183-343)$ & $205(193-217)$ & $265(183-409)$ & 0,735 \\
\hline D-dimer (ng/mL) & $490(204-7790)$ & $338(166-641)$ & $191(12-1100)$ & $35(6-63)$ & $283(6-7790)$ & 0,533 \\
\hline
\end{tabular}


Sakarya Tip Dergisi 2021;11(4):823-828

ORHAN ve Ark., COVID-19 ve İmmüno-Hematoloji

Tablo 2: COVID-19 tanılı çocuklarda lenfosit alt grupları ile doğal öldürücü hücrelerin mutlak sayısal değerleri ve yüzdesel olarak medyan değerleri* $^{*}$

\begin{tabular}{|c|c|c|c|c|}
\hline & 2-5 Yaş $(n=8)$ & 5-10 Yaş $(\mathrm{n}=5)$ & 10-16 Yaş (n=7) & 16 Yaş üstü $(n=2)$ \\
\hline Lenfosit (\%) & $57(40-71) \uparrow$ & $41(31-60)$ & $43(32-48)$ & $49(48-50)$ \\
\hline Lenfosit $(/ \mu \mathrm{L})$ & $4283(1835-7205) \uparrow$ & $2874(2128-4459)$ & $2273(1955-2938)$ & $2538(1990-3085)$ \\
\hline CD3+-T Cell (\%) & $72(51-84)$ & $75(68-79)$ & $74(66-79)$ & $72(67-77)$ \\
\hline CD3+- T Cell $(/ \mu \mathrm{L})$ & $3033(1330-4532)$ & $2141(1651-3014)$ & $1663(1281-2306)$ & $1792(1532-2052)$ \\
\hline CD3+CD4+Th Cell (\%) & $36(29-38)$ & $39(29-45)$ & $42(32-48)$ & $40(37-42)$ \\
\hline CD3+CD4+Th Cell $(/ \mu \mathrm{L})$ & $980(489-1641) \downarrow$ & $870(642-968)$ & $689(482-1105)$ & $703(648-757)$ \\
\hline CD3+CD8+Tc Cell (\%) & $28(13-41) \uparrow$ & $26(21-35)$ & $28(23-36)$ & $24(23-24)$ \\
\hline CD3+CD8+Tc Cell $(/ \mu \mathrm{L})$ & $681(220-1309)$ & $550(452-895)$ & $567(297-601)$ & $422(371-472) \downarrow$ \\
\hline CD4/CD8 Oranı & $1,3(0,9-2,2) \downarrow$ & $1,2(1,0-2,1)$ & $1,6(0,9-1,8)$ & $1,7(1,6-1,7) \downarrow$ \\
\hline CD19+ B Cell (\%) & $12(5-35) \downarrow$ & $12(9-18)$ & $9(6-13)$ & $16(11-21)$ \\
\hline CD19+B Cell $(/ \mu \mathrm{L})$ & $444(83-1702) \downarrow$ & $397(251-520)$ & $172(132-370) \downarrow$ & $427(217-636) \uparrow$ \\
\hline $\begin{array}{l}\text { CD3-CD16/56+ NK } \\
\text { Cell (\%) }\end{array}$ & $10(5-22)$ & $8(5-23) \downarrow$ & $11(4-21)$ & $9(8-9) \downarrow$ \\
\hline $\begin{array}{l}\text { CD3-CD16/56+ NK Cell } \\
(/ \mu \mathrm{L})\end{array}$ & $362(174-1585) \uparrow$ & $185(155-1030) \downarrow$ & $265(122-468)$ & $219(179-259) \downarrow$ \\
\hline
\end{tabular}

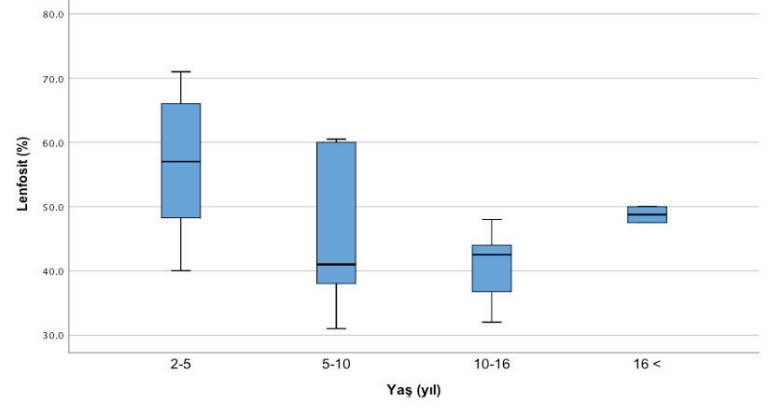

Şekil 1. COVID-19 tanılı çocukların yaş gruplarına göre lenfosit yüzdelerinin kutu grafiği

\section{TARTIŞMA}

COVID-19 tanısı alan çocuklarda en sık yapılabilen ve ulaşılabilir test hemogramdır. İran'da 200 yetişkin şüpheli hastanın alındığı çalışmada COVID-19 için pozitif RTPCR'lı olguların öngörülmesinde laboratuvar parametrelerinin doğruluğu değerlendirilmiş ve lökopeni ile birlikte nötrofilinin olması prediktif bir bulgu olarak yorumlanmıştır. ${ }^{9}$ Çalışmamızda çocuklarda bunu destekleyecek bir kanıt bulamadık. Çin’de yapılan bir çalışmada da ağır olan ve olmayan vakaların arasında yapılan korelasyon analizinde WBC sayısı açısından bir fark olmadığı rapor edilmiştir. ${ }^{10}$ Lökosit sayısı normal iken lenfopeni gelişebildiği de gösterilmiştir. Çalışma grubumuzda lökopeni gözlenen çocuklar olmakla birlikte hiçbirinde lenfopeni gözlemedik. Wuhan şehrinde 3. düzey sağlık hizmeti verilen iki hastaneden toplanan verilerde, hastaların yatıs sırasındaki bilgileri değerlendirildiğinde; ölen 109 COVID-19 hastanın iyileşen 116 hastaya göre daha yüksek WBC sayıları ile başvurduğu anlaşılmıştır. Ölen grubundaki hastaların önemli ölçüde daha düşük lenfosit sayısı ile seyrettiği ve lenfosit/WBC oranının istatistiksel olarak anlamlı bir şekilde düşmeye devam ettiği gözlenmiştir. ${ }^{11}$ Lenfopeni, daha sonra Türkiye Cumhuriyeti Sağlık Bakanlığı tarafından yayınlanan tanı ve tedavi rehberinde de risk faktörü olarak ele alınmıştır. Eozinofil sayısında azalma da diğer viral enfeksiyonlara nazaran farklı olarak tespit edilmiş bulgulardan biridir. ${ }^{12}$ Yine bizim hasta grubunda eozinopeni gözlemedik. 
Tedavi sırasında trombositleri anlamlı derecede yüksek olan hastaların ortalama hastanede yatış sürelerinin daha uzun olduğu, tedavi sırasında hastaların daha yüksek PLR'lerinin olmasının ortalama hastanede yatış günlerini uzattı̆̆ı bildirilmiştir. Hastaların PLR’sinin, COVID-19'lu hasta izleminde yeni bir gösterge sağlayabileceği ve sitokin fırtınası derecesini gösterebileceği şeklinde yorumlanmıştır. ${ }^{13}$ Hiçbir hastamızın ciddi bir sitokin fırtınası yaşamaması PLR değerlerimizin normal olması ile ilişkilendirilebilir.

COVID-19 hastaları ve kontrol grupları arasında PT ve aPTT değerleri arasında anlamlı bir fark olmadığı gösterilmiştir. ${ }^{14}$ Biz de bu çalışmamızda hasta grubunda bir uzunluk saptamadik.

Wuhan şehrinde yapılan 225 hastalık çalışmada, ölen hastaların \%6,4'ü yaygın intravasküler pıhtılaşma (DIC) komplikasyonu göstermiştir. ${ }^{11}$ Fibrinojen yüksekliği de rapor edilen hematolojik bulgular arasındadır. ${ }^{15}$ Çocuklardan oluşan hasta grubunda fibrinojen yüksekliği saptamadık. Sepsise bağlı koagülopati kriterlerini taşıyan ağır hastalık durumunda heparin uygulanması, DIC ve venöz tromboembolizm riski nedeniyle bazı uzmanlar tarafından önerilmiştir. 449 hastanın 99'una düşük molekül ağırlıklı heparin (LMWH) verilmiş ve bu hastaların 28 günlük mortalitesi, kullanılmayanlara oranla istatistiksel olarak daha düşük bulunmuştur. ${ }^{16}$ SARS CoV-2 ile enfekte 94 hastanın pıhtılaşma fonksiyonu, 40 normal insan ile kıyaslandığında D-Dimer ve FDP düzeylerinin anlamlı derecede yüksek olduğu tespit edilmiştir. ${ }^{17} \mathrm{Bu}$ virüs ile enfekte ve pnömoni tanısı alan 30 sağlık çalışanının (22 doktor, 8 hemşire) irdelendiği bir makalede lökopeni, lenfopeni ve D-Dimer yüksekliği saptanmıştır. ${ }^{18} 3$ hastamızda D-dimer yüksekliği saptamakla birlikte tüm grupların medyan değerleri göz önüne alındığında sonuçlarımızda yükseklik saptamadık ve hiç biri yoğun bakım ihtiyacı yaşamadı.

Literatürde, T lenfositlerin sayısal olarak azaldığı hem CD4 hem de CD8'in azaldığı görülmüştür. Sağlıklı bireylerle karşılaştırıldığında CD4/CD8 oranının COVID-19 hastalığında değişmediği, CD8 düzeyinin anlamlı olarak yükseldiği saptanmıştır. ${ }^{19} \mathrm{Bu}$ sonuç, COVID-19 enfeksiyonu ile tetiklenen hücresel bağışıklık tepkilerinin, CD8'in aşırı ekspresyonu ve sitotoksik T lenfositlerinin hiperaktivasyonu yoluyla geliştirildiğini düşündürmektedir. Çocuklarda CD8 aşırı ekspresyonu görmememiz, çocukların neden hastalığı erişkinlere oranla daha hafif geçirdiğini izah edebilir. Erişkin çalıșmalarında B hücreleri ve NK hücreleri de bu hastalıkta azalmaktadır. ${ }^{20}$ Çalışmamızda ise azalmak bir yana bazı gruplarda artması yine çocuk ve erişkin farkını ortaya koymaktadır. Bu hastalığın immünopatolojisi ortaya konabilirse immünoterapisi de mümkün olacaktır. ${ }^{21}$

\section{SONUÇ}

Hemogram çalışıldığında basitçe elde edilecek platelet-lenfosit oranı (PLR) sitokin firtınasının bir göstergesi olarak kullanılabilir ve çocuklarda CD8 aşırı ekspresyonu olmaması COVID-19 hastalığını neden erişkinlere oranla daha hafif geçirdiklerinin nedeni olabilir. NK hücrelerinin artışı da bu hastalıktan koruyucu mekanizmalardan biri olabilir. 
Sakarya Tip Dergisi 2021;11(4):823-828

ORHAN ve Ark., COVID-19 ve İmmüno-Hematoloji

\section{References}

1. Shen $Q$, Guo W, Guo T, et al. Novel coronavirus infection in children outside of Wuhan, China. Pediatr Pulmonol. 2020. doi:10.1002/ppul.24762

2. ÖZDEMIR Ö, PALA A. Çocuklarda COVID-19 Enfeksiyonunun Tanısı, Tedavisi ve Korunma Yolları. Vol 4. Deneysel, Biyoteknolojik, Klinik ve Stratejik Sağ̆lk Araștırmaları Derneği; 2020:14-21. doi:10.34084/bshr.711208

3. Fan BE, Chong VCL, Chan SSW, et al. Hematologic parameters in patients with COVID-19 infection. Am J Hematol. 2020. doi:10.1002/ajh.25774

4. Chng WJ, Lai HC, Earnest A, Kuperan P. Haematological parameters in severe acute respiratory syndrome. Clin Lab Haematol. 2005;27(1):15-20. doi:10.1111/j.13652257.2004.00652.x

5. Zhang G, Zhang J, Wang B, Zhu X, Wang Q, Qiu S. Analysis of clinical characteristics and laboratory findings of 95 cases of 2019 novel coronavirus pneumonia in Wuhan, China: a retrospective analysis. Respir Res. 2020;21(1):74. doi:10.1186/s12931-020-01338-8

6. Wan S, Xiang Y, Fang W, et al. Clinical Features and Treatment of COVID-19 Patients in Northeast Chongqing. J Med Virol. 2020. doi:10.1002/jmv.25783

7. Chen $G, W u D, G u o W$, et al. Clinical and immunological features of severe and moderate coronavirus disease 2019. J Clin Invest. 2020;130(5):2620-2629. doi:10.1172/JCI137244

8. Ikincioğullari A, Kendirli T, Doğu F, Eğin Y, Reisli I. Peripheral blood lymphocyte subsets in healthy Turkish children. Turk J Pediatr. 2004;46(2):125-130.

9. Mardani R, Ahmadi Vasmehjani A, Zali F, et al. Laboratory Parameters in Detection of COVID-19 Patients with Positive RT-PCR; a Diagnostic Accuracy Study. Arch Acad Emerg Med. 2020;8(1):e43.

10. Zhou Y, Zhang Z, Tian J, Xiong S. Risk factors associated with disease progression in a cohort of patients infected with the 2019 novel coronavirus. Ann Palliat Med. 2020. doi:10.21037/apm.2020.03.26

11. Deng Y, Liu W, Liu K, et al. Clinical characteristics of fatal and recovered cases of coronavirus disease 2019 (COVID-19) in Wuhan, China: a retrospective study. Chin Med J. 2020. doi:10.1097/cm9.0000000000000824

12. $\mathrm{Li} Y X, W u W$, Yang T, et al. [Characteristics of peripheral blood leukocyte differential counts in patients with COVID-19]. Zhonghua Nei Ke Za Zhi. 2020;59(0):E003. doi:3760.10/ cma.j.cn112138-20200221-00114

13. Qu R, Ling $Y$, Zhang YH, et al. Platelet-to-lymphocyte ratio is associated with prognosis in patients with coronavirus disease-19. J Med Virol. 2020. doi:10.1002/jmv.25767

14. Sayyadi $M$, Khosravi M, Ghaznavi-Rad E. Contribution value of coagulation abnormalities in covid-19 prognosis: A bright perspective on the laboratory pattern of patients with coronavirus disease 2019. Eur Rev Med Pharmacol Sci. 2021;25(1):518-522. doi:10.26355/ eurrev_202101_24423

15. Li CX, Wu B, Luo F, Zhang N. [Clinical Study and CT Findings of a Familial Cluster of Pneumonia with Coronavirus Disease 2019 (COVID-19)]. Sichuan Da Xue Xue Bao Yi Xue Ban. 2020;51(2):155-158. doi:10.12182/20200360107

16. Tang N, Bai H, Chen X, Gong J, Li D, Sun Z. Anticoagulant treatment is associated with decreased mortality in severe coronavirus disease 2019 patients with coagulopathy. J Thromb Haemost. 2020. doi:10.1111/jth.14817

17. Han H, Yang L, Liu R, et al. Prominent changes in blood coagulation of patients with SARSCoV-2 infection. Clin Chem Lab Med. 2020. doi:10.1515/cclm-2020-0188

18. Liu M, He P, Liu HG, et al. [Clinical characteristics of 30 medical workers infected with new coronavirus pneumonia]. Zhonghua Jie He He Hu Xi Za Zhi. 2020;43(3):209-214. doi:10.3760/cma.j.issn.1001-0939.2020.03.014

19. Ganji A, Farahani I, Khansarinejad B, Ghazavi A, Mosayebi G. Increased expression of CD8 marker on T-cells in COVID-19 patients. Blood Cells, Mol Dis. 2020;83. doi:10.1016/j. bcmd.2020.102437

20. Wang F, Nie J, Wang H, et al. Characteristics of Peripheral Lymphocyte Subset Alteration in
COVID-19 Pneumonia. J Infect Dis. 2020;221(11):1762-1769. doi:10.1093/infdis/jiaa150 21. Chiappelli F. CoViD-19 Immunopathology \& Immunotherapy. Bioinformation. 2020;16(3):219-222. doi:10.6026/97320630016219 